International Review of Research in Open and Distributed Learning Volume 16, Number 2

April - 2015

\title{
Coursera's Introductory Human Physiology Course: Factors that Characterize Successful Completion of a MOOC
}

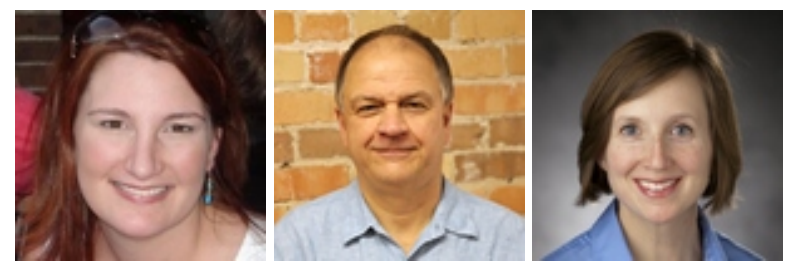

Deborah Engle, Chris Mankoff, and Jennifer Carbrey

\begin{abstract}
Since Massive Open Online Courses (MOOCs) are accessible by anyone in the world at no cost, they have large enrollments that are conducive to educational research. This study examines students in the Coursera MOOC, Introductory Human Physiology. Of the 33,378 students who accessed the course, around 15,000 students responded to items on the pre-course survey about their age, educational background, proficiency in English, and plans for participating in the course. We categorized students who completed the pre-course survey into groups based on the number of exams completed and corresponding course achievement level. We used Chi-square goodness of fit tests to analyze the distribution of students' responses on the pre-course survey and associated achievement level. Of the students who responded to the pre-course survey and passed with distinction, a larger percentage self-identified as fluent in English while a smaller percentage self-identified as beginners. Students with graduate degrees were more likely to pass the course or pass with distinction than students with only some college experience or a bachelor's degree. Students who completed either some or all exams were more likely to selfreport intention to complete all course activities than students who did not take any exams. A greater proportion of students who passed the course or passed with distinction posted two or more times on the course discussion forum. Understanding MOOC students and the characteristics that lead to their success will enable modification to courses for increased student achievement and may also inform teaching in the traditional classroom.
\end{abstract}

Keywords: Physiology; MOOC; online education 


\section{Introduction}

Massive Open Online Courses (MOOCs) are offered over the internet and are open to anyone in the world at no cost. There are several major MOOC providers such as edX, Udacity, and Coursera (Pappano, 2012). One of the main goals of MOOC providers is to provide free educational opportunities to people around the world.

One MOOC provider, Coursera, has partnered with more than 100 colleges and universities from all over the world to offer more than 600 courses in varying topics (Coursera, 2014). More than 5 million students have taken Coursera courses. Currently, students do not earn credit from the institution offering the course. However, students successfully completing the course receive a Statement of Accomplishment. In some Coursera courses, students can pay a fee to receive a Verified Certificate through the Signature Track. The identity of students on the Signature track is verified using their webcam and the pattern of their typing (Coursera, 2014).

Students in online university courses have higher attrition rates compared to face-to-face courses (Carr, 2000; Xu, 2014; Xu, 2011). Because there is no cost to enroll in a MOOC and registration is a simple process, completion rates for MOOCs are low compared to traditional online and face-toface courses. Many MOOC students do not plan to complete all components of the course when they enroll. There is no penalty for discontinuing a MOOC, particularly since the courses are not for credit towards a degree. However, a minority of students complete all of the required components of MOOCs and score well on the course assessments. One advantage of MOOCs over traditional university courses is that MOOCs enable students to choose how they want to participate in the course by allowing them to take as many components of the course as they choose.

Studies have been published examining the intent of students and how it compares with their completion of a MOOC. Koller (2013) showed that in one Coursera course, $74 \%$ of students who enrolled in the Signature Track, which includes paying a small fee, completed the course compared to a 9\% completion rate for students not enrolled in the Signature Track. A similar effect was seen in 2008 with two versions of an online course that was offered by the University of Manitoba to anyone in the world for credit or at no cost. The students taking the course for credit were much more likely to complete the course than those taking the identical open version (Fini, 2009).

\section{Research Question}

Research has begun to examine the characteristics of students who successfully complete MOOCs (Liyanagunawardena, 2013). For example, several studies have shown that a larger proportion of students who earned a course certificate also posted on the discussion forum (Breslow, 2013; Gillani, 2014; Ho, 2014; Kizilcec, 2013). Additionally, studies have shown that in some courses,

This work is licensed under a Creative Commons Attribution 4.0 International License. 
students who earn certificates tend to be older, more educated, and have previous experience in the field of study (Breslow, 2013; Ho, 2014).

The aim of our current study is to describe the student characteristics involved with the completion and earned level of achievement in the Coursera course, Introductory Human Physiology offered by Duke University. To accomplish this, we categorized students who completed the pre-course survey into groups based on the number of exams they completed and their corresponding course achievement level. This allowed us to examine demographic data of the students divided into groups based on both motivation and achievement. As a result of this unique method of dividing the students, we were able to gain insights about our student population that is unprecedented for studies of MOOCs thus far.

\section{Methods}

This study examines the first session of the Coursera course, Introductory Human Physiology, which began in February 2013. This study was approved for exemption by the Duke University School of Medicine Institutional Review Board.

\section{Course Details}

Introductory Human Physiology is a 12 week Coursera course based on a Duke University graduate course originally designed to teach physiology to biomedical engineering students. Topics include the physiology of the nervous system, skeletal muscle, cardiovascular system, respiratory system, endocrine system, reproductive system, gastrointestinal system, and the urinary system.

Each week, Coursera Introductory Human Physiology students were provided 2 to 8 video lectures that varied in length from 7 to 40 minutes. The majority of videos contained 1 to 3 invideo questions that served to summarize and/or highlight video content. Lecture notes and PowerPoint slides were also provided to the students. Multiple-choice problem sets were provided for most organ systems through the Coursera platform. These were optional and were not graded. Once the students submitted their responses to the problem set, they immediately received feedback about whether their answers were correct. Students could continue to attempt the problem sets until they answered all items correctly.

The course grade was based on average scores on three multiple-choice question exams. Each exam was administered in three parts of 15-20 questions each. Students were given 30 minutes to answer each part, and each part could be taken only once. Each exam was available to students for 1-2 weeks.

This work is licensed under a Creative Commons Attribution 4.0 International License. 
Students with an exam average of $70-84 \%$ passed the course and received a Statement of Accomplishment. Students with an $85 \%$ or higher average passed with distinction and earned a Distinction Statement of Accomplishment. Students had the option of paying a small fee to join the Signature Track which enables students to earn a Verified Certificate.

Students had access to a discussion forum on the Coursera website that allowed them to post questions or comments about the material and the course. The discussion forum consisted of several sub-forums specific to lectures, technical feedback, problem sets, etc. This architecture allowed for student comments and questions to be sorted by a specific topic. Course instructors and staff at Duke answered students' questions.

Via announcements on the course webpage and email, students were notified about pre-course and post-course surveys administered by Duke University using Qualtrics, a web-based survey system (Qualtrics, LLC). Students were informed that the survey participation was voluntary and that responses may be used for research purposes. Only data from the pre-course survey was analyzed due to a small number of responses to the post-course survey (about 1,100 respondents).

\section{Data Processing}

Data for the first session of Introductory Human Physiology were obtained from Coursera as a set of individual tables in either SQL or text format. Data from pre- and post-course surveys were obtained from the Qualtrics instance hosted by Duke University.

All source datasets were converted into SAS datasets using SAS 9.3®. The source data were merged using unique student identification numbers. We constructed three variables into the dataset: total number of course forum posts per student, an "all tests" indicator variable flagged those students who completed every test offered in the course, and a "some tests" indicator variable flagged those students who completed at least one test, but did not take every test offered.

The dataset was then de-identified by removing student name, email address, and IP address variables. Additionally, the Coursera-issued unique student identification number was replaced with a random student identification number created at Duke University.

The students who completed the pre-course survey were categorized into five groups:

1. students who did not complete any exams in the course,

2. students who completed some exams but not all exams,

3. students who completed all three exams but did not pass the course,

4. students who passed the course but did not earn distinction, and

5. students who passed the course with distinction.

This work is licensed under a Creative Commons Attribution 4.0 International License. 


\section{Data Analysis}

The distribution of student responses to various pre-course survey items, based upon their exam completion and achievement level groups, was analyzed. Since the responses on the survey were all categorical, all variables were treated as categorical. Using the chi-square goodness of fit test, the observed distribution of responses for a group was compared to the expected distribution of responses for all students who answered survey items. Significance was set at $\leq 0.05$ level. Only those observations with a p value $\leq 0.05$ are reported here. Student gender and ethnicity data were not available through the pre-course survey.

\section{Results}

\section{Descriptive Analysis}

Table 1 illustrates the exam completion and achievement level profile for students who accessed the Introductory Human Physiology course. The majority of students (84\%) who accessed the course did not complete any of the exams. $11 \%$ of students completed at least one part of an exam but did not complete all of the exams. A small percentage (about $2 \%$ ) of students who accessed the course completed all of the exams but did not pass the course. Another $2 \%$ of students passed the course without distinction, while only $1 \%$ of students passed the course with distinction. 
Table 1

Statistics from the First Session of Introductory Human Physiology

Number of students who $\quad 33,738$

accessed the course

Number of students who did $\quad$ 28,304 (84\%)*

not complete any exams

Number of students who

$3,778(11 \%)^{*}$

completed some exams but not

all

Number of students who

$620(1.8 \%)^{*}$

completed all exams but did

not pass

Number of students who

$698(2.0 \%)^{*}$

passed the course but did not

earn distinction

Number of students who 338 (1.0\%)*

passed the course with

distinction

Number of discussion forum $\quad 5,431$

posts

Number of students who $\quad 2,185(6.5 \%)^{*}$

posted on the forum

*as a percentage of the number of students who accessed the course

\section{Age}

15,046 students answered the pre-course survey question about age. Of these, $29.5 \%$ answered that they were between 18-25 years of age, 30.3\% answered 26-34 years of age, $17.4 \%$ answered $35-44$ years of age, $12.6 \%$ answered $45-54$ years of age, 7.6\% answered $55-64$ years of age, and $2.7 \%$ answered 65 years old or older. Students younger than 18 years old were not included. When students were divided into groups based on the number of exams they completed and based on their achievement in the course, chi-square goodness of fit analyses indicated there was no significant difference $(\mathrm{p}<.05)$ in the proportion of age groups across all achievement levels.

\section{English as a $1^{\text {st }}$ language}

In the pre-course survey, students were asked, "Is English your 1' language?" Among the 15,310 students who answered the question, the majority (56.9\%) answered "no". A Chi-square 
goodness of fit test indicated that a significantly lower proportion of students who reported as non-native English speakers completed all of the exams but did not pass (47.0\%) compared to all students who answered the question and reported as non-native English speakers (56.9\%), $\chi^{2}(1, n$ $=328)=4.1, \mathrm{p}<.05$.

\section{Level of English Proficiency}

Students who reported they were non-native English speakers were asked, "Please indicate your level of proficiency with the English language." Of the 6,537 students who answered the question, $43.1 \%$ self-identified as fluent, $33.7 \%$ as proficient, $20.7 \%$ as intermediate, and $2.5 \%$ as beginners (Fig. 1). Less than one quarter of students who answered that English was not their first language self-identified as intermediate or beginners in English. When the students were divided into groups based on how many exams they completed and their level of achievement, a chi-square goodness of fit test indicated there was a significantly higher proportion of students who selfidentified as fluent and earned distinction (49.5\%) compared to all students who answered the question $(43.1 \%), \chi^{2}(1, \mathrm{n}=111)=4.1, \mathrm{p}<.05$ (Fig. 1). Among students who completed all of the exams but did not pass the course, a statistically significant lower proportion self-identified as fluent (32.9\%) compared to all students $(43.1 \%), \chi^{2}(1, n=173)=4.1, p<.05$. Yet, a statistically significant higher proportion self-identified as intermediate (30.6\%) compared to all students (20.7\%) who answered the question $\left(\chi^{2}(1, n=173)=6.0, p<.05\right.$, Fig. 1). 


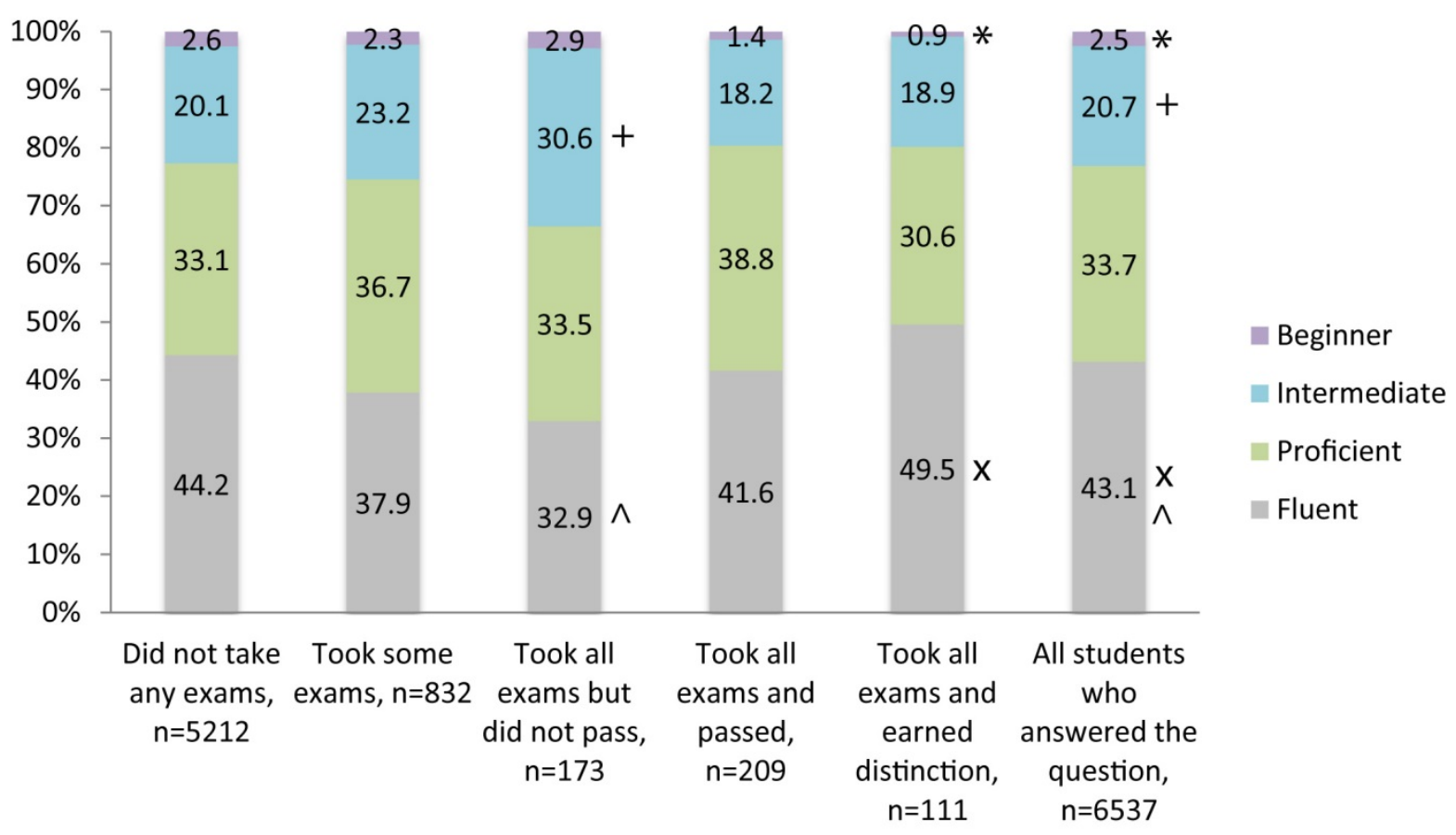

Figure 1. Students who answered that English was not their first language were asked to choose their level of proficiency with the English language. The responding students were divided into five different groups based on the number of exams they completed and whether or not they passed the course or passed with distinction. The bars show the percentage of students in each proficiency category based on the students' answers on the pre-course survey. The bar on the right shows the percentage of students in each category for all of the students who answered the question on the pre-course survey. The symbols to the right of each bar $\left(*,+, \mathrm{x},{ }^{\prime}\right)$ denote statistically significant differences between groups as assessed with the chi-square goodness of fit test with the $\mathrm{p}$ value $<0.05$. Groups marked with the same symbol denote two groups with statistically significant differences.

\section{Education}

Students who completed the pre-course survey were asked, "What is the highest level of education you have completed?" Of the 14,821 students who answered the question, $9.7 \%$ had completed high school or the equivalent, $20.3 \%$ had completed some college, $36.2 \%$ had completed a bachelor's degree, $23.4 \%$ had completed a master's degree, 5\% had completed a doctoral degree, and 5.3\% had completed a professional degree (Fig. 2). More than half of the students who answered the pre-course survey question had bachelor's or master's degrees. When the students were divided based on the number of exams they completed and whether or not they passed the course, there were a number of statistically significant differences in the education level of the groups (Fig. 2). Chi-square goodness of fit tests indicated there was a significantly smaller 
proportion of students with some college but not a bachelor's degree who passed the course (10.7\%) and passed the course with distinction (9.8\%) compared to all students who answered the question $(19.8 \%) \chi^{2}(1, \mathrm{n}=411)=5.1, \mathrm{p}<.05$ and $\chi^{2}(1, \mathrm{n}=214)=7.6, \mathrm{p}<.05$. In contrast, chisquare goodness of fit tests indicated there was a significantly larger proportion of students with a doctoral degree who passed the course without distinction (10.2\%) or who passed the course with distinction (15.4\%) compared to all students who answered the question $(5.0 \%) \chi^{2}(1, \mathrm{n}=411)=$ $5.3, \mathrm{p}<.05$ and $\chi^{2}(1, \mathrm{n}=214)=21.1, \mathrm{p}<.05$, Fig. 2$)$. Chi-square goodness of fit tests indicated students with a professional degree were statistically overrepresented in the group of students who completed all exams but did not pass (10.7\%) and in the students who passed with distinction (10.3\%) compared to all of the students who completed the pre-course survey (5.2\%) $\chi^{2}(1, n=328)=7.6, p<.05$ and $\chi^{2}(1, n=214)=5.3, p<.05$, Fig. 2$)$.

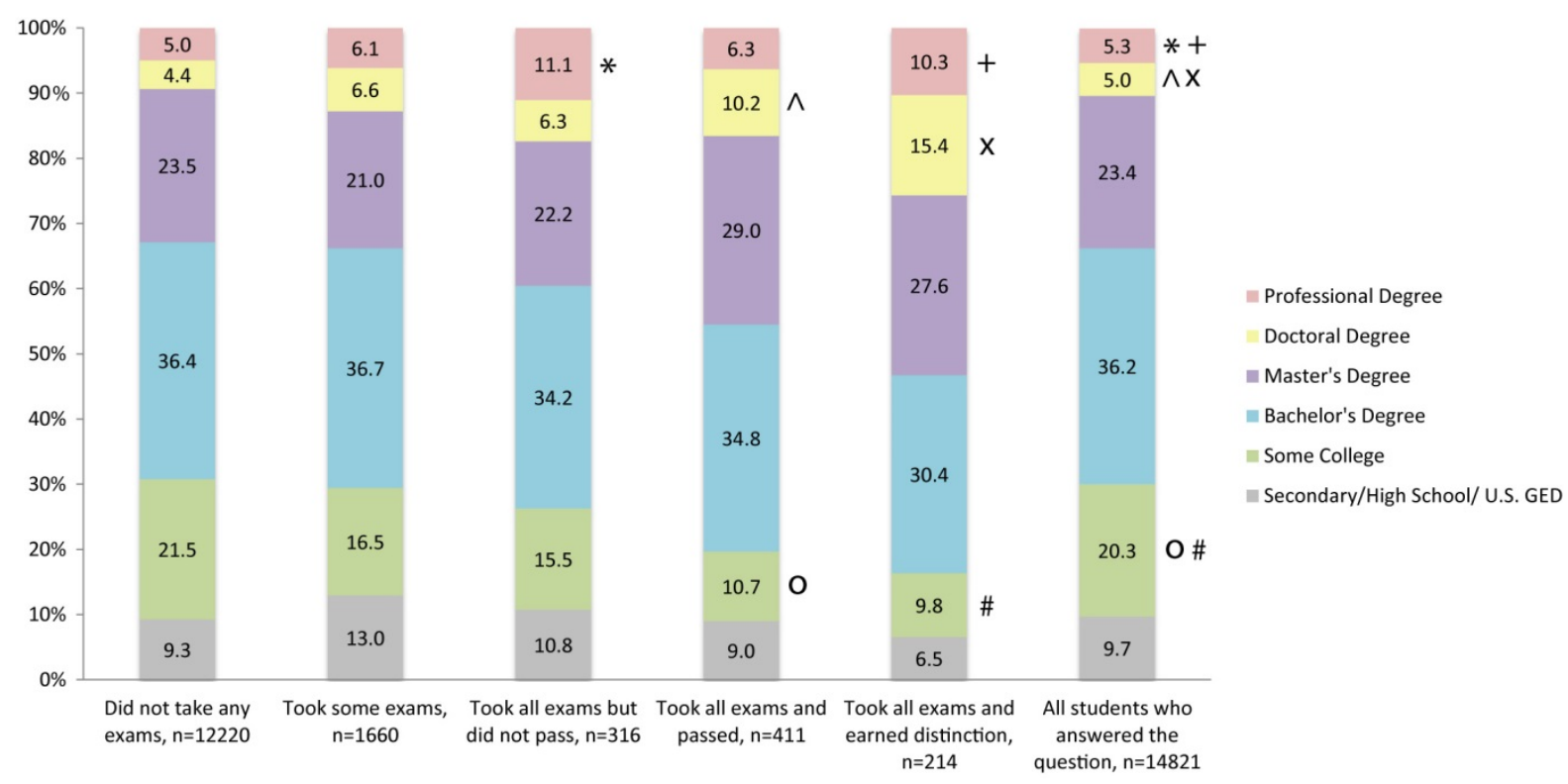

Figure 2. Students who submitted information on the pre-course survey about their highest completed level of education were divided into five different groups. Each bar is divided based on the percentage of students submitting each answer on the pre-course survey. The symbols to the right of the bars denote statistically significant differences between groups as assessed with the chi-square goodness of fit test with the $\mathrm{p}$ value $<0.05$. Groups marked with the same symbol denote two groups with statistically significant differences.

\section{Academic Background}

Within the pre-course survey, students were also asked about their academic background. 15.1\% of students responded that humanities best described their academic background while $17.8 \%$ answered natural sciences, $13.9 \%$ answered social sciences, $30.6 \%$ answered health sciences, 
$11.6 \%$ answered professional, and $11.0 \%$ answered technical (Fig. 3). Among the students who took some exams but not all, a chi-square goodness of fit test indicated the students with a health science background (42.7\%) were a significantly higher proportion compared to their proportion among all students who answered the question (30.6\%) $\chi^{2}(1, \mathrm{n}=1325)=6.7, \mathrm{p}<.05$ (Fig. 3). Another chi-square goodness of fit test indicated that students with a social sciences background (7.0\%) were a significantly smaller proportion of students who completed all exams but did not pass $(13.9 \%) \chi^{2}(1, n=243)=4.1, p<.05$ (Fig. 3). Among the students who earned distinction in the course, students with a humanities background were underrepresented $\left(7.5 \%\right.$ versus $15.1 \%, \chi^{2}$ $(1, \mathrm{n}=174)=3.8, \mathrm{p}=.05)$ and students with a natural sciences background were overrepresented (32.8\% versus $17.8 \%, \chi^{2}(1, \mathrm{n}=174)=15.2, \mathrm{p}<.05$ Fig. 3$)$.

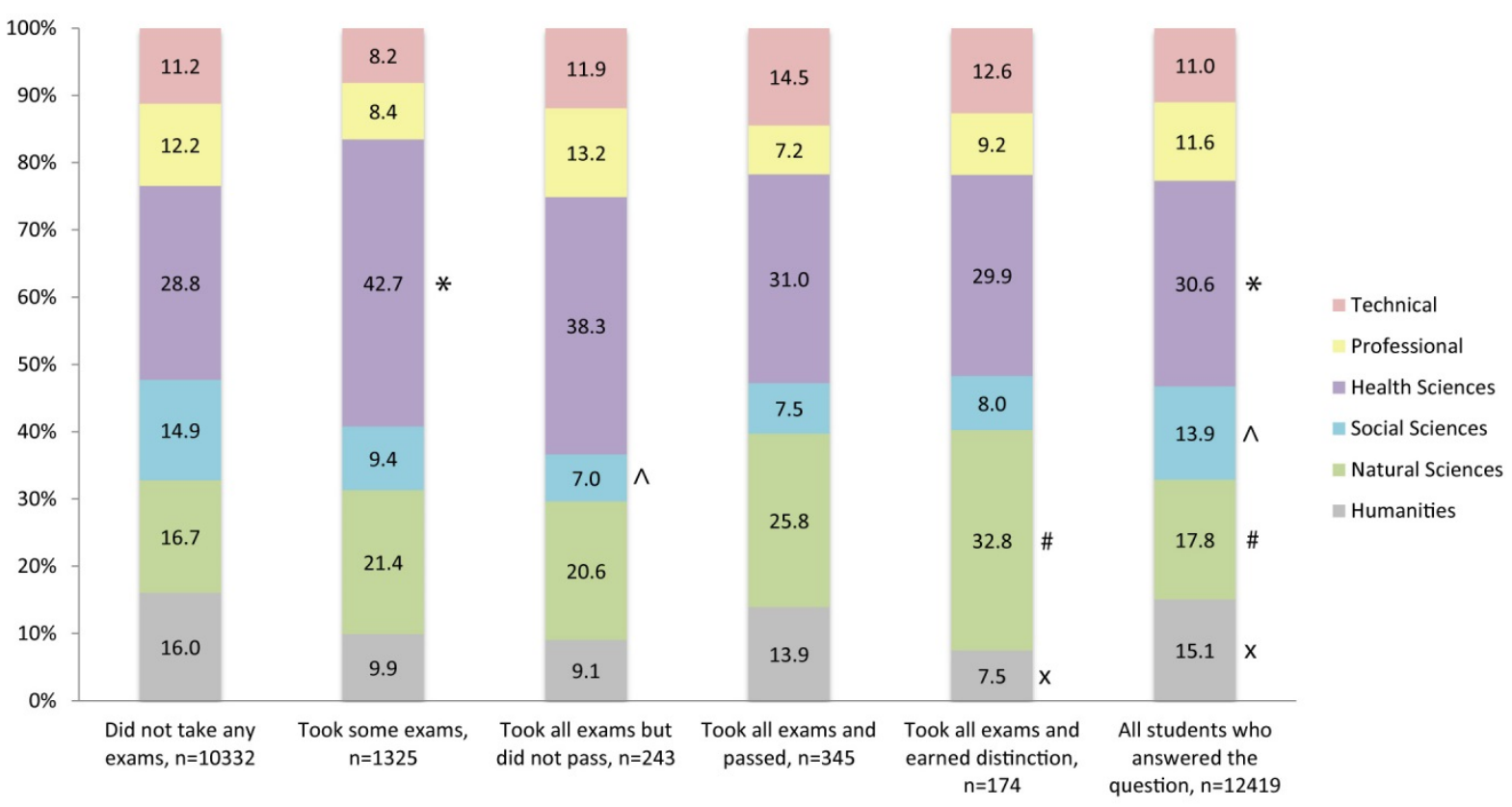

Figure 3. Students who answered the pre-course survey question, "Which of the following describes your academic background?" were divided into five different groups based on the number of exams they completed and whether or not they passed the course or passed with distinction. The bars show the percentage of students in each group that chose each answer on the pre-course survey. The symbols to the right of the bars denote statistically significant differences between groups as assessed with the chi-square goodness of fit test with the $p$ value $<0.05$. Groups marked with the same symbol denote two groups with statistically significant differences.

\section{Previous Experience}

The pre-course survey included a question about the students' previous experience with the course's subject area. Of the 15,234 students who answered the question, $23.5 \%$ responded that they were mostly new to the subject, $25.6 \%$ liked to explore the subject on their own, $35.5 \%$ had completed some coursework in physiology or had some work experience, and $15.4 \%$ responded that they had a degree in physiology or significant work experience in the field (Fig. 4). Students 
who had completed some physiology coursework or who had some work experience were overrepresented in the group of students who passed the course with distinction $(48.4 \%$ versus $35.5 \%, \chi^{2}(1, n=213)=6.3, p<.05$, Fig. 4). Students with significant work experience or a degree in physiology were overrepresented in the group of students who passed the course without distinction (22.8\%) compared to all students (15.4\%), $\chi^{2}(1, n=328)=5.0, \mathrm{p}<.05$, Fig. 4).

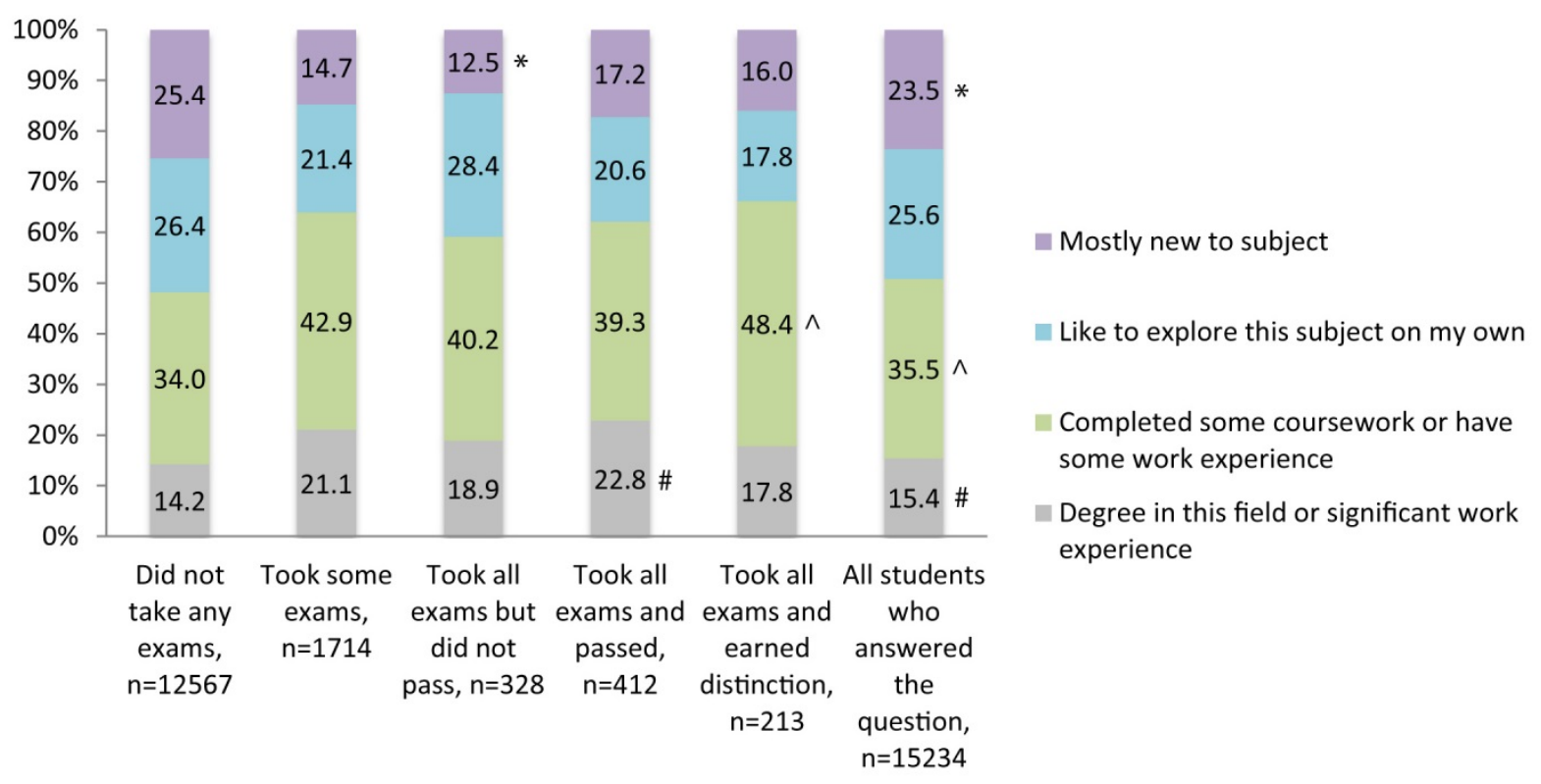

Figure 4. Students who answered the pre-course survey question, "What best describes your previous experience in the course's subject area?" were divided into five different groups. The bars show the percentage of students in each group that chose each answer on the pre-course survey. The symbols to the right of the bars denote statistically significant differences between groups as assessed with the chi-square goodness of fit test with the $p$ value $<0.05$. Groups marked with the same symbol denote two groups with statistically significant differences.

\section{Student Intentions}

Much has been written in the press about the small percentage of students who complete MOOCs (Haynie, 2014; Morrison, 2014; Waldrop, 2013). Our pre-course survey included questions about the students' intentions for the course. When asked how many of the course activities the students planned to complete, 1.6\% answered none, 18.2\% answered few, 35.4\% answered most, and $44.8 \%$ answered all (Fig. 5).

When the responses to this question about intention to complete course activities was disaggregated according to achievement level, the mean proportion of students who intended to complete all activities was significantly higher (59.1\%) among students who took at least one exam than all students who answered the question (44.8\%), $\chi^{2}(1, n=667)=7.9, p<.05$ (Fig. 5). Moreover, the mean proportion of students who took at least one exam and who responded they 
would complete few activities was significantly lower (8.4\%) than all students who answered the question (18.2\%), $\chi^{2}(1, \mathrm{n}=667)=6.8, \mathrm{p}<.05$ (Fig. 5). Students who took at least one exam were more likely to have responded that they would complete the course and less likely to have responded that they would complete few activities.

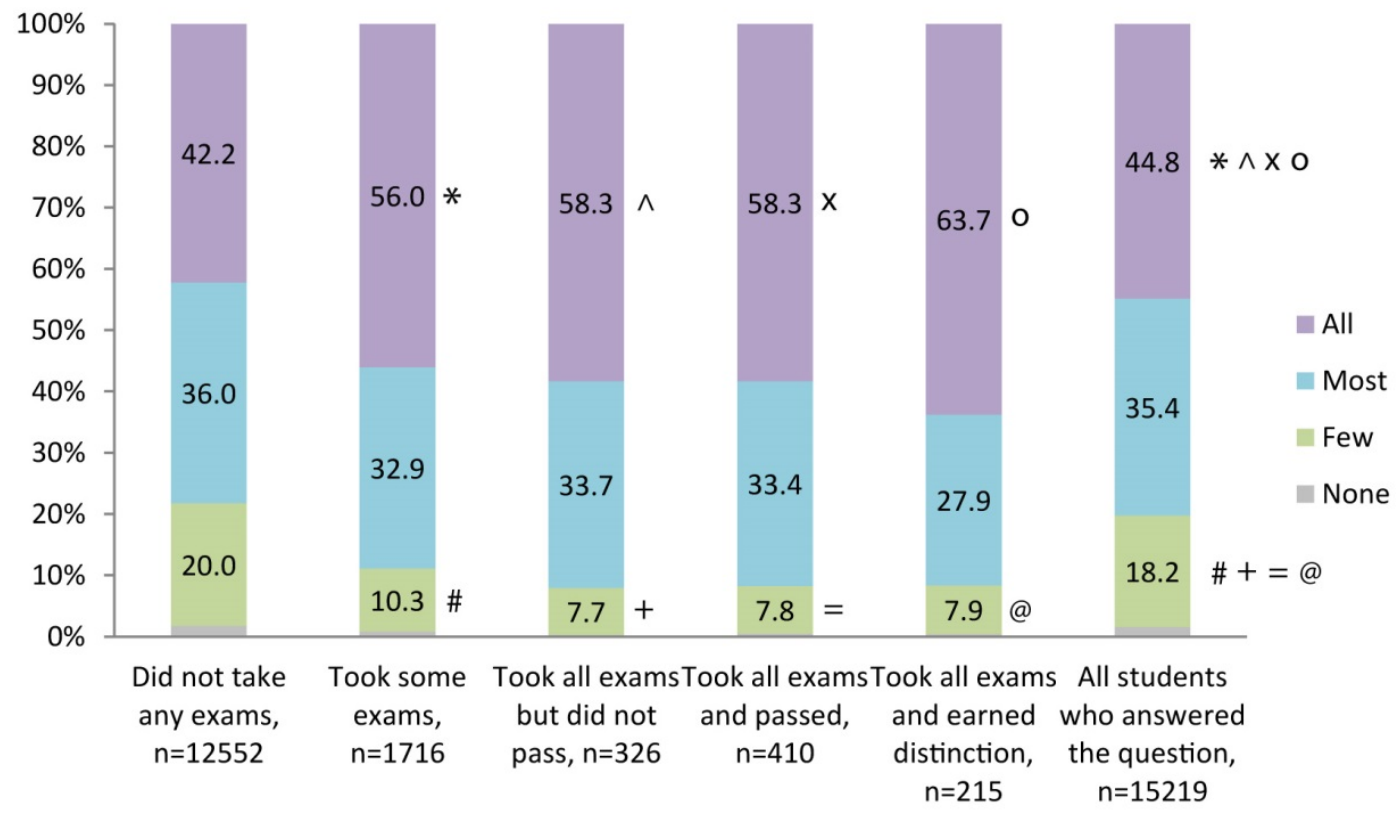

Figure 5. Students were asked the pre-course survey question, "How much of the course activities do you plan to complete?" Each bar is divided based on the percentage of students submitting each answer on the pre-course survey. The symbols to the right of the bars denote statistically significant differences between groups as assessed with the chi-square goodness of fit test with the $\mathrm{p}$ value $<0.05$. Groups marked with the same symbol denote two groups with statistically significant differences.

Students were also asked how many hours they anticipated spending on the course each week. Of the 15,226 students who answered the question, 20.6\% answered 1-3 hours, 47.7\% answered 4-6 hours, $22.4 \%$ answered 7-9 hours, $6.5 \%$ answered 10-12 hours, and 2.7\% answered 13 or more hours (Fig. 6). Students who expected to spend 1-3 hours on the course and completed all exams but did not pass (12.6\%), passed the course (10.2\%), and passed with distinction (7.0\%), were a significantly smaller percentage compared to all students who answered the question (20.6\%), $\chi^{2}$ $(1, \mathrm{n}=326)=3.9, \mathrm{p}<.05$ and $\chi^{2}(1, \mathrm{n}=413)=7.2, \mathrm{p}<.05$ and $\chi^{2}(1, \mathrm{n}=215)=11.8, \mathrm{p}<.05$, (Fig. 6). A significantly larger percentage of students who completed all the exams but did not pass answered 7-9 hours (31.6\%) compared to all students who answered the question (22.4\%), $\chi^{2}(1, \mathrm{n}$ $=326)=5.8, \mathrm{p}<.05$, (Fig. 6). 


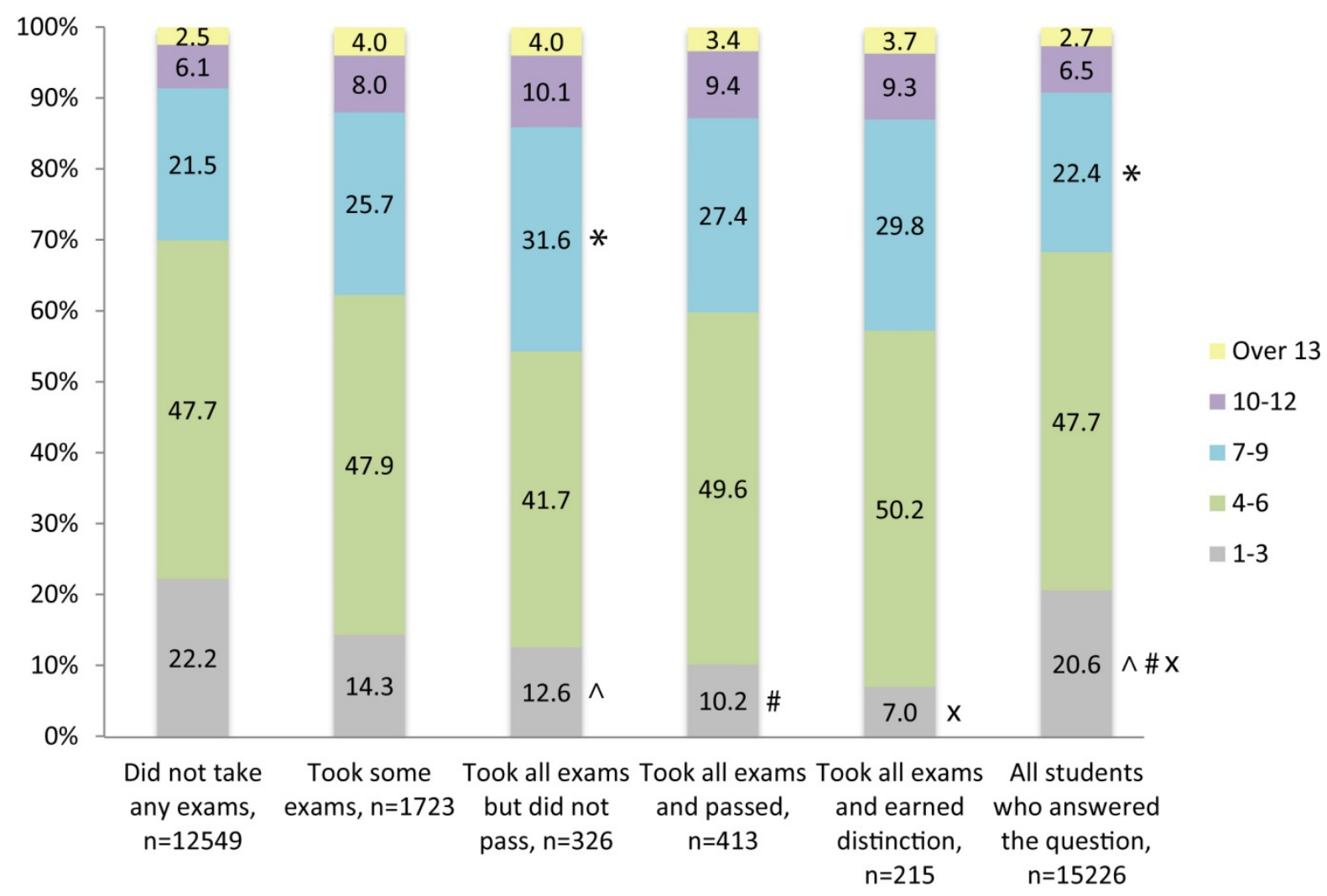

Figure 6. Students who answered the pre-course survey question, "How many hours per week will you be spending on this course?" were divided into five different groups based on the number of exams they completed and whether or not they passed the course or passed with distinction. The bars show the percentage of students in each group that chose each answer on the pre-course survey. The symbols to the right of the bars denote statistically significant differences between groups as assessed with the chi-square goodness of fit test with the $p$ value $<0.05$. Groups marked with the same symbol denote two groups with statistically significant differences.

\section{Forum Activity}

The number of times a student posted on the course discussion forum was also examined. $6.5 \%$ of the students who accessed the course posted on the discussion forum (Table 1). Since the vast majority of students who did not take any exams did not post on the discussion forum, that group was not included in our analysis. Of the 5,430 students who completed at least one exam, $80.2 \%$ did not post on the forum, $10.0 \%$ posted once, $8.6 \%$ posted $2-10$ times, and $1.1 \%$ posted more than 10 times (Fig. 7).

When students were disaggregated into groups based on the number of exams they completed and whether or not they passed the course, the majority of all four groups did not post on the discussion forum (Fig. 7). Of the students who passed the course without distinction, a greater 
proportion posted on the forum 2-10 times (15.7\%) or more than 10 times (2.3\%) compared to all students $\left(8.6 \%\right.$ and $1.1 \%$, respectively), $\chi^{2}(1, \mathrm{n}=214)=6.0, \mathrm{p}<.05$ and $\chi^{2}(1, \mathrm{n}=214)=4.0, \mathrm{p}<$ .05, (Fig. 7). The proportion was even higher for students who passed with distinction as $19.5 \%$ posted 2-10 times and 6.2\% posted more than 10 times $\left(\chi^{2}(1, n=128)=14.8, \mathrm{p}<.05\right.$ and $\chi^{2}(1, n$ $=128)=25.3, p<.05$,Fig. 7 ). Among the students who completed all exams but did not pass, $15.5 \%$ posted 2-10 times compared to $8.6 \%$ who completed at least one exam $\left(\chi^{2}(1, n=186)=6.0\right.$ $\mathrm{p}<.05$, Fig. 7).

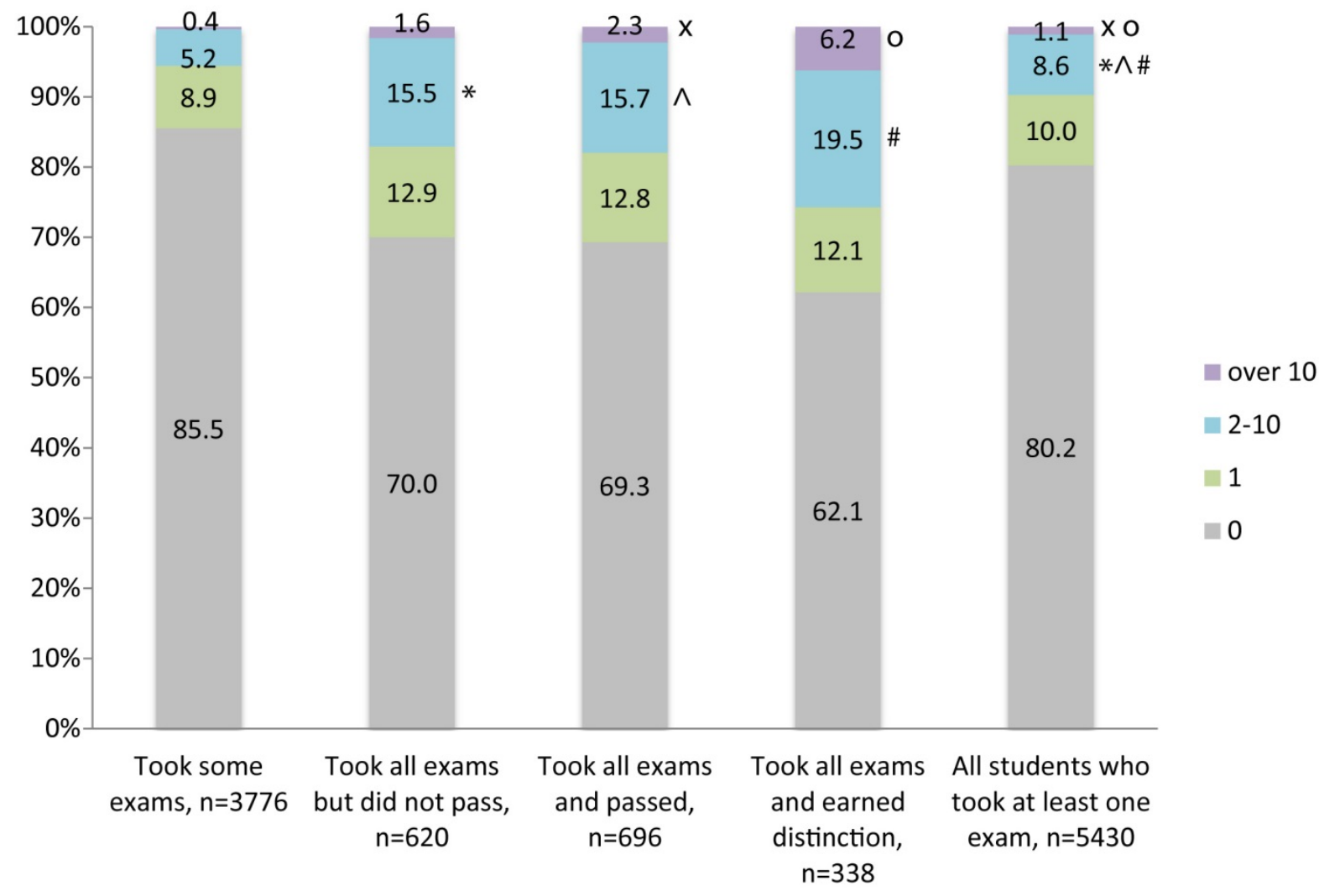

Figure 7. Students who completed at least one exam were divided into five different groups based on the number of exams they completed and whether or not they passed the course or passed with distinction. The bars show the percentage of students in each category based on the number of times they posted on the forum. The symbols to the right of the bars denote statistically significant differences between groups as assessed with the chi-square goodness of fit test with the $\mathrm{p}$ value $<0.05$. Groups marked with the same symbol denote two groups with statistically significant differences. 


\section{Discussion}

Of the 33,738 students who accessed the 1st session of Introductory Human Physiology, 16\% completed at least a part of an exam and 3\% passed the course. This pass rate is lower than the roughly $5 \%$ of students who pass Coursera courses in general (Koller, 2013) and the median pass rate of $6.5 \%$ for MOOCs in general (J ordan, 2014). Since our course is based on a graduate course, a lower pass rate may be expected.

Our study was focused primarily on student responses to the pre-course survey. Since most survey items had around 15,000 responses, we captured data from about $45 \%$ of our student population. We divided the students into five groups based on the number of exams completed and course achievement level. Because of this division, we were able to gather data that is unprecedented in the MOOC literature. Several studies have compared students who successfully completed a MOOC to those who accessed varying amounts of the course material (Ho, 2014; Kizilcec, 2013). However, we gained additional information by examining the characteristics of students who completed all of the exams but did not pass the course and those who were able to pass with distinction.

\section{Age}

Several studies have shown that older students score higher on assessments examining selfdirected learning readiness which may be important for MOOC retention and achievement (Alspach, 1991; Dixon, 1992; Eyer, 1993; Frisby, 1991; Morris, 1995; Reio, 2005). In addition, a study of students in an online undergraduate business course showed that age correlated positively with the final grade in the course (Wojciechowski, 2005). In our study, there was no significant difference with respect to age in the composition of groups of students separated based on the amount of the course they completed and their achievement level. This has been reported in the literature for other MOOCs (Breslow, 2013; Root Kustritz, 2014). It is possible that since so few students intend to complete MOOCs and there is no penalty for withdrawing, the effects of age and self-directed learning readiness are not evident.

In a study of the first 17 courses available on the edX platform, certificate earners had a median age that was two years older than the median age for the courses (Ho, 2014). Since our pre-course survey asked the students to select their age range, we cannot calculate median age. However, the median age range of students who did not pass the course and those students who passed without distinction was 26-34 years old. The median age range of students who passed with distinction was 35-44 years old.

\section{English Proficiency}

Of the students who took all of the exams but did not pass, non-native English speakers who were fluent were a smaller percentage and intermediate students were a larger percentage compared to all students who answered the question. Of the students who earned distinction, fluent students

This work is licensed under a Creative Commons Attribution 4.0 International License. 
were a larger percentage and beginner students were a smaller percentage compared to all nonnative English speakers that answered the question. Although our results suggest that a student's proficiency in English does influence their likelihood of earning distinction, the proficiency of the group of students who passed the course without distinction was very similar to the proficiency of all students who answered the question. Perhaps translations of the course or increased time for exams can increase achievement among beginner and intermediate English speakers. Following the completion of the first session of Introductory Human Physiology additional translated resources have been made available to students.

\section{Education}

Students with doctoral degrees were a greater proportion of the students who passed the course or passed the course with distinction. This is not surprising considering the course is based on a Duke University graduate course, albeit an introductory one. This effect of educational background on student achievement has also been observed for other MOOCs (Breslow, 2013; Ho, 2014). In addition, several studies have shown that students with advanced degrees score higher on assessments examining self-directed learning readiness which may be important for MOOC completion and achievement (Alspach, 1991; Dixon, 1992; Durr, 1992; Martin, 1992).

\section{Academic Background}

Among students who earned distinction, students with a natural sciences background were overrepresented and those with a humanities background were underrepresented. These results suggest the academic background of a student influences the achievement level obtained in our course. This fairly subtle effect of experience on student achievement has been observed in another MOOC (Breslow, 2013). Despite this effect, a substantial number of students were able to successfully complete the course without a natural sciences or health sciences background. Providing more basic biology resources for students who need more background information may improve performance in our course for certain students.

\section{Previous Experience}

Not surprisingly, students with at least some experience in physiology were more likely to pass the course or pass the course with distinction. A previous study of an undergraduate economics course shows that student experience in a specific topic reduced attrition and increased performance (Anderson, 1994). In our study, 17\% of students who passed the course and answered the pre-course survey stated that they were mostly new to the subject, indicating that the course was not excessively difficult for beginners.

A recent study of an introductory physics MOOC suggested that many students learned a similar amount no matter what their background with the subject matter (Colvin, 2014). For instance, students that showed low ability at the beginning of the course learned the same amount as students with high ability at the beginning of the course (Colvin, 2014). Although this was not the focus of our study, our results somewhat support their conclusions since students with at least

This work is licensed under a Creative Commons Attribution 4.0 International License. 
some experience in physiology were more likely to pass the course. Further studies of students who take our MOOC multiple times could help us understand the patterns of student behavior that lead to successful completion based on previous experience with physiology. This may also allow us to counsel students on strategies for eventually completing the course.

\section{Student Intentions}

Among the students who took at least one exam, a higher percentage answered that they would complete all of the course activities and a lower percentage answered that they would complete few. Even though $44.8 \%$ of students intended to complete all three exams, only $6 \%$ of the students who answered the question actually completed them. This suggests that many students are not able to accurately predict how much of the course they will complete.

It would be informative to survey students who intended to complete the course but stopped participating, in order to determine what prevented them from completing the course. One advantage of MOOCs is that they are cost-free. This provides students with the freedom to decide, as well as continually reassess, how much of the course they would like to complete as they progress through the course.

Of the students who took all of the exams, a smaller percentage said that they would spend only 13 hours on the course each week. This suggests that more students who completed the course anticipated that they would need to spend more than 1-3 hours a week on the course. This may be due in large part to the fact that Coursera informed the students that the course will require 6-8 hours per week on the webpage for the course.

In a study of a subset of students in 3 MOOCs from San J osé State University, student effort was the strongest predictor of student success (Firmin et al., 2014). Factors such as student demographics and characteristics did not impact whether or not a student was successful in a significant way (Firmin et al., 2014). Our study only focuses on the number of hours a student intends to spend on the course. Further study into the number of hours needed to be successful would be helpful in trying to counsel students in how to be successful in our course.

\section{Forum Activity}

Of the students who either passed the course or earned distinction, a higher proportion of them posted on the discussion forum multiple times than the students who were less successful. However, across all groups, the majority of students did not post on the discussion forum. In a published analysis of three MOOCs, the students who completed most of the assessments were more likely to have participated in the discussion forums (Kizilcec, 2013). In two different studies of edX MOOCs, the students who earned a certificate were more likely to have posted on the forum (Breslow, 2013; Ho, 2014). In a business strategy MOOC, the students who posted on the forum were more likely to have successfully completed the course, although the majority of forum participants did not complete the course (Gillani, 2014). The number of posts on the discussion

This work is licensed under a Creative Commons Attribution 4.0 International License. 
forum may be another way to measure engagement in the course similar to the number of exams a student takes. Studies of students participating in distance education suggest that participation in discussion forums can play a positive role in student retention and achievement (Baxter, 2012). In our course, posting on the forum was not a required portion of the course. Although there were statistically significant differences between groups of students, the differences were not drastic enough to allow anticipation of a student's level of achievement based on the number of discussion forum posts.

\section{Conclusions and Future Studies}

With the exception of age, every demographic variable and pre-course survey question had statistically significant differences between groups of students. Most of these observations are fairly expected. Variables such as English proficiency, educational background, experience in the subject of the course, intentions of the student, and the number of forum posts make a student more likely to achieve at a certain level in the course. However these differences are not large enough to be able to anticipate student achievement based on student characteristics.

Unfortunately, information about gender and ethnicity were not available for this study. Although the gender of the students was an item on the pre-course survey, we were not able to obtain the data. The ethnicity or race of the students was not an item on the pre-course survey. Examining the effect of these variables on the completion and achievement in our course and in other MOOCs requires further study.

Improving the completion and passing rates of MOOCs will require understanding why some students lose motivation to complete the course and why some students have difficulty passing the course even though they have adequate motivation. In an attempt to answer these questions, we included a series of items on our post-course survey targeted to students who did not complete or pass our course. These students indicated on a Likert-type scale ( $1=$ no effect, $2=$ slightly more likely, $3=$ much more likely) whether certain adjustments would have made it more likely that they would have successfully completed the course. Aggregate mean results from 456 respondents show that reducing the weekly time commitment ( $\bar{X}=1.8$ ) and making the course easier ( $\bar{X}=$ 1.7) are course adjustments that might have had some effect on completion. Results also show that making the credential more valuable ( $\bar{X}=1.4)$, stating the needed prerequisites clearly ( $\bar{X}$ $=1.4$ ), making the course length shorter ( $\bar{X}=1.3$ ), and making the course more difficult ( $\bar{X}=$ 1.1) may or may not have an effect on completion. Altogether, these results suggest that there are multiple reasons why more students did not successfully complete our course and that it is a complex issue. More specific questions about a student's motivations throughout the course should enable improved course design aimed at increasing achievement among students who lose motivation. This could be accomplished through frequent surveying of students about their reasons for their level of involvement in the course.

This work is licensed under a Creative Commons Attribution 4.0 International License. 
Our study, as well as studies from others (Breslow, 2013; Ho, 2014), have shown that student characteristics such as proficiency in English, highest level of education, and academic background can influence achievement in MOOCs. The impact of modifying courses to improve performance among students with certain characteristics should be examined. For example, studies could examine how providing additional translated resources in a course effects completion and performance. Similarly, studying how providing background material for students who may not yet have a bachelor's degree or experience in the topic affects retention and achievement.

Understanding the factors that lead students who intend to complete a course to leave a course may enable modifications that increase retention. Improving retention in online courses through modification has been described previously (Chyung 2001). However, many of the modifications made in the study involved providing individual attention which is not practical in a MOOC with an enrollment of 30,000 students. Due to the large enrollment of MOOCs, however, even small changes in retention and achievement will impact a large number of students.

\section{Acknowledgements}

We would like to thank Emma Jakoi and Kim Manturuk for their critical reading of our manuscript. 


\section{References}

Alspach, J . G. (1991). The self-directed learning readiness of baccalaureate nursing students (Order No. 9133189). Available from ProQuest Dissertations \& Theses Global. (303937537). Retrieved from http:// search.proquest.com/ docview/303937537?accountid=10598

Anderson, G., Benjamin, D., Fuss, M. A. (1994). The determinants of success in university introductory economics courses. J ournal of Economic Education, 25(2), 99- 119.

Baxter, J . (2012). Who am I and what keeps me going? Profiling the distance student. International Review of Research in Open and Distance Learning, 13(4), 107-129.

Breslow, L., Pritchard, D.E., DeBoer, J., Stump, G.S., Ho, A.D., Seaton, D.T. (2013). Studying learning in the worldwide classroom research into edX's first MOOC. Research \& Practice in Assessment, 8(Summer), 13-25.

Carr, S. (2000). As distance education comes of age, the challenge is keeping the students. The Chronicle of Higher Education, 46(23), A39-A41.

Castaño-Muñoz, J . Sancho-Vinuesa, T., Duart, J . M. (2013) Online interaction in higher education: Is there evidence of diminishing returns? The International Review of Research in Open and Distributed Learning, 14(5), 240-257.

Cheung, L., Kan , A. (2002). Evaluation of factors related to student performance in a distancelearning business communication course. J ournal of Education for Business, 77(5), 257263.

Chyung, S. Y. (2001). Systematic and systemic approaches to reducing attrition rates in online higher education. American J ournal of Distance Education, 15(3), 36-49.

Colvin, K. F., Champaign, J ., Liu, A., Zhou, Q. Fredericks, C., Pritchard, D.E. (2014). Learning in an introductory physics MOOC: All cohorts learn equally, including an on-campus class. International Review of Research in Open and Distance Learning, 15(4), 263-283.

Coursera. (2014). Coursera website. from https:// www.coursera.org/

Dixon, W. B. (1992). An exploratory study of self-directed learning readiness and pedagogical expectations about learning among adult inmate learners in Michigan (Order No. 9431234). Available from ProQuest Dissertations \& Theses Global. (303987882). Retrieved from http:// search.proquest.com/docview/303987882?accountid=10598

This work is licensed under a Creative Commons Attribution 4.0 International License. 
Durr, R. E. (1992). An examination of readiness for self-directed learning and selected personnel variables at a large midwestern electronics development and manufacturing corporation (Order No. 9231896). Available from ProQuest Dissertations \& Theses Global. (304011996). Retrieved from http:// search.proquest.com/docview/ 304011996?accountid=10598

Eyer, J . (1993). Self-directed continuing learning characteristics and perceptions of professional autonomy in senior baccalaureate nursing students (Order No. 9324971). Available from ProQuest Dissertations \& Theses Global. (304063537). Retrieved from http:// search.proquest.com/docview/304063537?accountid=10598

Fini, A. (2009). The technological dimension of a massive open online course: The case of the cck08 course tools. International Review of Research in Open and Distance Learning, 10(5), 26.

Firmin, R., Schiorring, E., Whitmer, J., Willett, T., Collins, E. D., \& Sujitparapitaya, S. (2014). Case study: Using MOOCs for conventional college coursework. Distance Education, 35(2), 178-201.

Frisby, A. J . (1991). Self-directed learning readiness in medical students at the ohio state university (Order No. 9130477). Available from ProQuest Dissertations \& Theses Global. (303946039). Retrieved from http:// search.proquest.com/docview/ 303946039?accountid=10598

Gillani, N., Eynon, R. (2014). Communication patterns in massively open online courses. Internet \&Higher Education, 23, 18-26.

Haynie, D. (2014). Experts debate the impact of MOOCs on education. US News and World Report. Retrieved from http://www.usnews.com/ education/onlineeducation/articles/2014/06/06/ experts-debate-the-impact-of-moocs-on-education

Ho, A. D., Reich, J ., Nesterko, S., Seaton, D. T., Mullaney, T., Waldo, J ., \& Chuang, I. (2014). HarvardX and MITx: The first year of open online courses. HarvardX and MITx Working Paper No. 1. Retrieved from http:// harvardx.harvard.edu/multiple-coursereport

J ordan, K. (2014). Initial trends in enrolment and completion of massive open online courses. The International Review of Research in Open and Distance Learning, 15(1), 133-159.

Kizilcec, R. F., Piech, C., Schneider, E. (2013). Deconstructing disengagement: Analyzing learner subpopulations in massive open online courses. Paper presented at the Proc. 3rd Int'l Conference on Learning Analytics and Knowledge (LAK '13), Leuven, Belgium.

This work is licensed under a Creative Commons Attribution 4.0 International License. 
Koller, D., Ng, A., Do, C., Chen, Z. (2013, May/J une 2013). Retention and intention in massive open online courses. Educause Review, 48, 62-63.

Liyanagunawardena, T. R., Adams, A.A., Williams, S.A. (2013). MOOCs: A systematic study of the published literature 2008-2012. The International Review of Research in Open and Distance Learning, 14(3), 202-227.

Martin, J . L. H. (1992). Self-directed learning and health promoting lifestyles (Order No. 9306246). Available from ProQuest Dissertations \& Theses Global. (303968989). Retrieved from http:// search.proquest.com/ docview/ 303968989?accountid=10598

Morris, S. S. (1995). The relationship between self-directed learning readiness and academic performance in a nontraditional higher education program (Order No. 9530074). Available from ProQuest Dissertations \& Theses Global. (304211856). Retrieved from http:// search.proquest.com/docview/ 304211856?accountid=10598

Morrison, N. (2014). The future of MOOCs in the classroom. Forbes. Retrieved from http:// www.forbes.com/ sites/nickmorrison/2014/06/25/the-future-of-moocs-in-the-1118-classroom/

Pappano, L. (2012, November 2, 2012). The year of the MOOC. The New York Times.

Reio, T. G., Jr., Davis, W. (2005). Age and gender differences in self-directed learning readiness: a developmental perspective. International J ournal of Self-directed Learning, 2(1), 40-49.

Root Kustritz, M. V. (2014). Canine theriogenology for dog enthusiasts: Teaching methodology and outcomes in a massive open online course (MOOC). J ournal of Veterinary Medical Education, 41(1), 9-18. doi: 10.3138/jvme.0813-112R1

Waldrop, M. M. (2013, March 14, 2013). Campus 2.0. Nature, 495, 160-163.

Wojciechowski, A., Palmer, L. B. (2005). Individual student characteristics: Can any be predictors of success in online classes? Online J ournal of Distance Learning Administration, 8(2), 13. Retrieved from http:// www.westga.edu/ distance/ ojdla/ summer82/ wojciechowski82.htm

Xu, D., J aggars, S. S. (2014). Performance gaps between online and face-to-face courses: Differences across types of students and academic subject areas. The J ournal of Higher Education, 85(5), 633-659.

Xu, D., J aggars, S. S. (2011). The effectiveness of distance education across Virginia's Community Colleges: Evidence from introductory college-level math and English courses. Educational Evaluation and Policy Analysis, 33(3), 360-377. 
Coursera's Introductory Human Physiology Course: Factors that Characterize Successful Completion of a MOOC Engle, Mankoff, and Carbrey

(C) Engle, Mankoff, and Carbrey

\section{Athabasca University $\mathbf{I}$}

(c) (i) 